\title{
Desafios terapêuticos das "bolsites" Inflamação do reservatório ileal
}

\section{Idblan Carvalho de Albuquerque}

Há mais de trinta anos a proctocolectomia total com a confecção de reservatório ileal (RI) com anastomose ao canal anal foi idealizada para os pacientes com polipose adenomatosa familiar (PAF) e retocolite ulcerativa (RCU)1 com o objetivo de evitar uma ileostomia terminal e definitiva por meio do RI1-3. Atualmente ainda recomenda-se a realização do RI com anastomose ao canal anal e estomia derivativa para os pacientes com RCU4.

Após o fechamento da ileostomia derivativa, o RI passa a funcionar como o substituto do reto. Do ponto de vista funcional, é importante o conhecimento de que o reto em condições fisiológicas normais elimina $200 \mathrm{ml}$ de água em até três evacuações diárias. Após a confecção do RI o indivíduo passa a eliminar aproximadamente $700 \mathrm{ml}$ de fezes amolecidas ou líquidas em uma media de 4-8 evacuações por dia ${ }^{5}$. A urgência evacuatória ocorre em cerca de $10 \%$ dos pacientes e $47 \%$ dos pacientes necessitarão do uso de medicamentos anti-diarreicos ${ }^{3,4,10}$.

Dentre as disfunções do RI a inflamação inespecífica da mucosa do reservatório ou bolsite é a complicação mais frequente (quadro $1)^{2,10}$. A real incidência da bolsite é de difícil determinação pois depende dos critérios de definição da mesma, da exatidão da avaliação e do tempo de segmento no pós-operatório. A bolsite ocorre em $49 \%$ dos pacientes no segmento de 10 anos e em $70 \%$ dos indivíduos em 
até vinte anos após a cirurgia ${ }^{6}$, sendo frequente o primeiro episódio de bolsite no primeiro ano de pós-operatório de fechamento da ostomia derivativa (figura 1$)^{5}$.

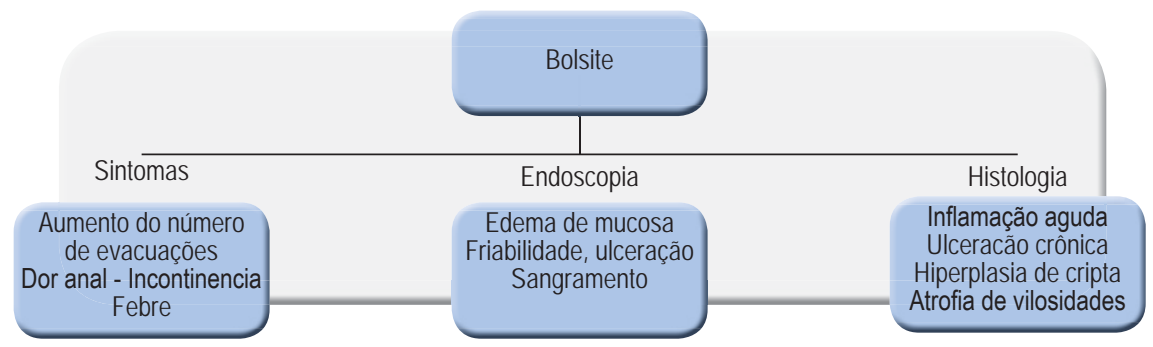

Figura 1 - Caracterização da bolsite

A etiologia da inflamação do RI é ainda pouco compreendida entre as hipóteses já sugeridas, a proliferação bacteriana decorrente da estase fecal a teoria mais aceita como a responsável pelas as alterações inflamatórias da mucosa intestinal ${ }^{7,10}$. Nos pacientes com bolsite (Figura 2) é recomendado o estudo do RI por meio de endoscopia e exames de imagem (RNM de pelve ou bolsograma) com o objetivo de excluir complicações cirúrgicas tais como deiscência nas linhas de suturas com formação de abcesso pélvico, estenose da anastomose e isquemia ${ }^{2,8}$.

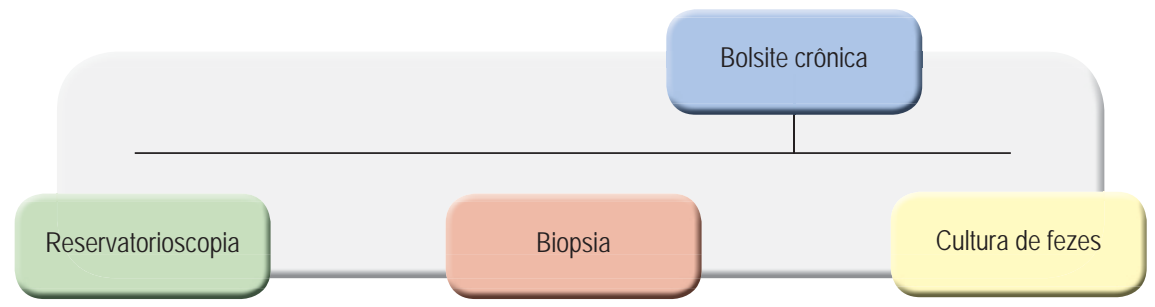

Figura 2 - Abordagem diagnóstica da bolsite

Outro diagnóstico diferencial da disfunção do RI é a permanência da mucosa do reto distal que quando inflamado (cuffitis) provoca sintomas semelhantes aos da bolsite e é responsável por 9\% dos casos desta afeccão. Existe ainda um grupo de pacientes que apresentam manifestações clínicas de doença de Crohn após terem sido submetidos a RI por retocolite ulcerativa, este número pode variar entre 2,7 


\begin{tabular}{|l|}
\hline Quadro 1 - Disfunção do reservatório ileal \\
\hline - Bolsite \\
\hline - Infecção (p.ex.: C. difficile) \\
\hline - Cuffitis \\
(inflamação da mucosa retal remanescente) \\
\hline - Doença de Crohn na bolsa \\
\hline
\end{tabular}

\begin{tabular}{|l|}
\hline \multicolumn{1}{|c|}{ Quadro 2 - Fatores de risco de bolsite } \\
\hline Manifestações extraintestinalis \\
\hline Colangite esclerosante primaria \\
\hline Pancolite de longa duração \\
\hline p-ANCA \\
\hline NOD2/CARD15 \\
\hline
\end{tabular}

a $13 \%$ dos pacientes inicialmente operados por $\mathrm{RCU}^{2,5}$.

Os fatores de risco para o desenvolvimento de bolsite relacionados com RCU podem ser observados ainda no pré-operatório e estão distribuídos na tabela 2. Os aspectos técnicos da cirurgia como o tipo de reservatório não influenciam o aparecimento de bolsite ${ }^{2,9}$.

Em conclusão, a disfunção do reservatório ileal na forma de bolsite é uma quadro clínico frequente após o fechamento da estomia de proteção. É importante ainda salientar que antes do tratamento medicamentoso se faz necessária a confirmação do diagnóstico através do estudo endoscópico, histológico e cultura de fezes. Dentre os diagnósticos diferencias estão bolsite por infecção, síndrome da bolsa irritável, doença de Crohn e cuffitis.

\section{Referências bibliográficas}

1. Parks AG, Nicholls RJ: Proctocolectomy without ileostomy for ulcerative colitis. Br Med J 1978. 2: 85-88.

2. Kent A, Keshav S. Managing Intractable Proctitis and the Problematic Pouch. Dig Dis 2014. 32: 427-437.

3. Fazio VW, el al: lleal pouch-anal anastomoses complications and function in 1005 patients. Ann Surg 1995. 222: 120-127.

4. Shen B, et al. Irritable pouch syndrome: a new category of diagnosis for symptomatic patients with ileal pouch-anal anastomosis. Am J Gastroenterol 2002. 97: 972-977.

5. Van Assche G, el al: Second european evidence-based consensus on the diagnosis and management of ulcerative colitis. Part 3: special situations. JCC 2013. 7:1-33.

6. Tekkis PP, Nicholls RJ. Ileal pouch disfunction: diagnosis and management. Gastroenterol Clin N Am 2008. 37: 669-683.

7. Shen B, Lashner BA. Diagnosis and treatment of pouchitis. Gastroenterology Hepatology 2008. 4(5): 355-361.

8. Francone TD, Champagne B. Considerations and complications in patients undergoing ileal pouch anal anastomosis. Surg Clin N Am 2013. 93/ 107-143.

9. Beliard A, Prudhomme M. Ileal reservoir with ileo-anal anastomosis: Long-term complications. J. Visceral Surgery 2010. 147: e137-e144.

10.Sherman J, Greenstein AJ, Greenstein AJ. Ileal J Pouch Complications and Surgical Solutions: A Review. Inflamm Bowel Dis 2014. 20:1678-1685. 